\title{
Addition of optional sign language in optometry schools for improved eye care for the deaf
}

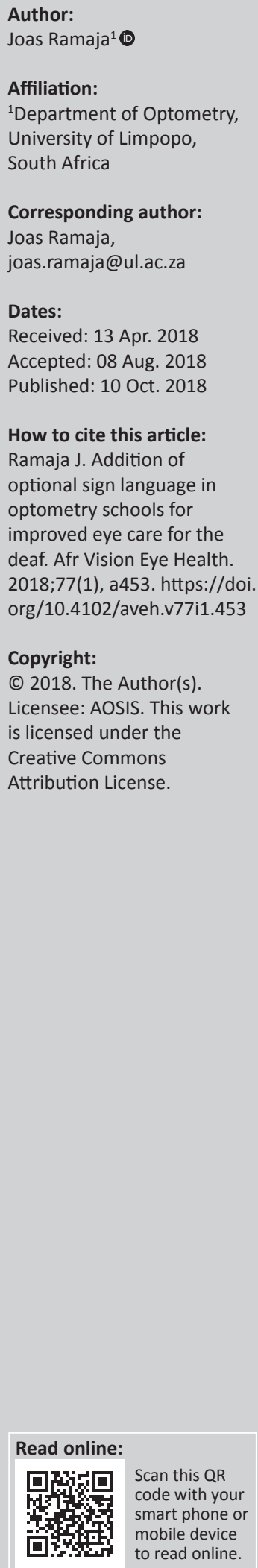

Background: Often, a deaf patient walks into an optometrist's practice seeking help with his / her eyes. There is a high likelihood that poor communication between patient and healthcare professional will influence the final product dispensed. This has been the personal experience of the author over the years in private practice.

Objectives: The article aims to start a debate on the quality of service given to a section of the population. The optometric services given to the deaf are in a way compromised by the communication barrier between patient and healthcare professional.

Method: A review of several studies on provision of healthcare services to the deaf was conducted. Further information was included on the importance of vision to the deaf.

Results: Eighteen full-text articles from around the world were included. The review found that the deaf use sight to compensate for their loss of hearing.

Conclusion: Deaf people rely on the sense of sight to make up for hearing loss. Training optometry graduates in sign language will improve the provider-patient communication with the deaf, thereby preventing the prevalence of deaf-blindness, which is an impediment to both development and education. A debate must be initiated on where the language can be incorporated into the already congested training programme.

\section{Introduction}

It is often the case that a deaf patient will enter an optometric practice for eye care. In more than 20 years of practicing optometry, the author has come across several such patients, and the communication barriers between practitioner and patient have a direct impact on the outcome, and this affects the quality of service the patient receives. The author would always rely on the writing skills of the deaf patient, only to find that there are those with limited or no writing skills at all, which made patient care even more difficult. As Harmer said, good provider-patient communication is fundamental to achieving positive treatment outcomes. ${ }^{1}$ Therefore, do optometrists allow the broken communication between them and the deaf patient to compromise the quality of service given? Optometrists will always rely on objective assessment in cases of communication breakdown, but how often do you have to alter your findings after a subjective evaluation? How do we give the deaf more say in their evaluation?

\section{Literature search}

The term 'deaf' refers to hearing loss that profoundly limits the ability to hear and understand speech, even with amplification; 'hard of hearing' refers to those with hearing loss who are able to get some linguistically useful information from sound, with or without amplification. ${ }^{2}$ Studies have indicated that the prevalence of ocular abnormalities among the deaf and hearing impaired is higher than among the general population..$^{2,3}$ It has been suggested that this association relates to the close anatomical relationship of the retina and the cochlea, which develop from the same embryonic layer. Typically, sight is the main sense used to compensate for deafness even though some knowledge is acquired via tactile and olfactory senses. In every child as well as in adults, much of their knowledge is obtained through the senses of sight and hearing;, when one of these senses is seriously impaired, the other is used to compensate. As the degree of impairment increases, the role of the remaining senses becomes progressively more significant. Thus, the deaf child may compensate by making greater use of the eyes, which means even a mild refractive error may reduce the visual efficiency of the child. Unfortunately, it may be difficult for the deaf patient to receive routine eye care services because of the communication problems ${ }^{4}$ that normally exist between eye care service providers and the deaf.

According to Harmer, deaf people visit health care providers more frequently than do hearing persons, but report less satisfaction with the health services they receive. ${ }^{1}$ Satisfaction with the 
provider-patient communication improves adherence to treatment regimens. ${ }^{5,6}$ Otherwise deaf patients could very well be at great risk of poor patient-provider communication, and that can interfere with achieving positive patient outcomes. ${ }^{7}$ It is also probably because of the language barrier that the deaf tend to have less health care knowledge; this is because of having fewer health education opportunities than the average hearing patient. ${ }^{1}$ It is therefore not uncommon for the deaf patient to wait too long to seek medical help because of lack of basic information. ${ }^{8}$

Deafness is a common sensorial deficit in the world; one of every 500-1000 newborns have permanent bilateral profound hearing loss. ${ }^{9}$ Deaf people can be divided into pre-lingual and post-lingual categories, depending on when the person lost his or her hearing. Pre-lingual deaf people lost their hearing before learning a spoken language; they usually use visual communication methods that include sign language. Post-lingual deaf people may have acquired some spoken language, so they may communicate by speech or in combination with sign language; they may also use lip-reading, which is also not easy as only $30 \%-$ $45 \%$ of spoken speech is visible externally, so most of what is said is missed.10,11 Post-lingual deaf adults may have a range of reading and writing skills, but pre-lingual deaf may have little or none at all. ${ }^{8}$ Both groups rely on sign language for their communication. Sign language is not derived from English or any other spoken language. It communicates ideas, not individual words. Natural sign languages are autonomous linguistic systems, independent of the spoken languages with which they may coexist in a given community. ${ }^{12}$ Therefore, sign language is not a nonverbal form of the spoken language. Sign languages are expressed with the hands, arms and face and are understood through the eyes, ${ }^{13}$ making optimal vision a requirement for effective communication. It is also important on the part of the hearing population to understand that the deaf will not automatically understand and read written language. ${ }^{8}$

\section{Conclusion}

Seeing that the deaf population rely mostly on their sense of sight to make up for their hearing loss, an effort must be made to expose eye care service providers to communication skills with the deaf. This will go a long way to preventing the prevalence of deaf-blindness, which affects not only communication but also the development and education of the patient; a child who is hearing and visually impaired is significantly more debilitated, being less able to lip read, less cooperative and less capable of manual tasks than hearing impaired children with normal vision. ${ }^{14}$ Research has shown that much of a child's learning depends upon listening to speech and other environmental sounds and most of the learning that is necessary for speech development takes place during the first two years of life, ${ }^{15}$ for a deaf child, vision is key to learning. Therefore, a deaf child is dependent on vision to develop efficient communication skills and explore the surrounding world..$^{14}$
Optometry as part of primary health care service will therefore benefit from basic knowledge of sign language. (One university in South Africa has reviewed its language policy to incorporate an African language at undergraduate level.) Exposing optometry graduates to sign language will go a long way towards making the profession relevant in providing a service to a community that puts more value to their vision than we can imagine. Hearing and vision are responsible for $95 \%$ of environmental cognition; because affected children are dependent on their visual sensation, correction of visual problems in deaf patients is very important. ${ }^{16}$ As the degree of impairment increases, the role of the remaining senses becomes progressively more significant; the deaf population compensate by making greater use of visual perceptual cues than their hearing peers, and thus even a mild refractive error may reduce the visual cues available to the deaf., ${ }^{2,17,18}$ It is therefore important to diagnose ocular anomalies early so that interventions can be undertaken to maximise vision; ${ }^{18}$ the quality of the service will improve with improved communication. Improved communication will also assist with timely referrals when needed.

This article is a call to optometrists to debate the exclusion of a section of the population from comprehensive eye care because of breakdown in communication. Again, one in every 500-1000 newborns has permanent bilateral profound hearing loss. ${ }^{9}$ Sign language lessons will therefore not go to waste.

\section{Acknowledgements Competing interests}

The author declares that he has no financial or personal relationships that may have inappropriately influenced him in writing this article.

\section{References}

1. Harmer L. Health care delivery and deaf people: Practice, problems and recommendations for change. J Deaf Studies Deaf Educ. 1999;4(2):73-110. $\mathrm{https}$ ///doi.org/10.1093/deafed/4.2.73

2. Regenbogen L, Godel V. Ocular deficiencies in deaf children. J Pediatr Ophthalmol Strabismus. 1985;22:231-233.

3. Abah ER, Oladigbolu KK, Samaila E, Merali H, Ahmed AO, Abubakar TH. Ophthalmologic abnormalities among deaf students in Kaduna, Northern Nigeria. Ann Afr Med. 2011;10(1):29-33. https://doi.org/10.4103/1596-3519.76573

4. Osaiyuwu AB, Ebeigbe JA. Prevalence of visual disorders in deaf children in Benin City. J Nigerian Optom Assoc. 2009;15:20-23.

5. Kane RL. Understanding health care outcomes research. Gaithersburg, MD: Aspen Publications; 1997

6. Brown JB, Boles M, Mullooly JP, Levinson W. Effect of clinician communication skills training on patient satisfaction: A randomized, controlled trial. Ann
Intern Med. 1999;131(11):822-829. https://doi.org/10.7326/0003-4819-131-11199912070-00004

7. Berry JA, Stewart AJ. Communicating with the deaf during the health examination visit. J Nurse Pract. 2006;509-515. https://doi.org/10.1016/j.nurpra.2006.06.013

8. Cohen M, Phillips J. Genetic approach to evaluation of hearing loss. Otolaryngol Clin N Am. 2012;45(1):25-39. https://doi.org/10.1016/j.otc.2011.08.015

9. Davies MC, Channon BT. Deaf patients in the medical imaging department: A qualitative study. J Diagn Radiography Imag. 2004;5(2):99-106. https://doi org/10.1017/S1460472804000069

10. Iezzoni LI, O'Day BL, Killeen M, Harker $\mathrm{H}$. Communicating about health care: Observations from persons who are deaf or hard of hearing. Ann Intern Med. 2004;140(5):356-363. https://doi.org/10.7326/0003-4819-140-5-200403020-00011

11. Lucas C. Sign language: Variation. Elsevier; 2006, pp. 354-358. 
12. Mayberry RI, Squires B. Sign language: Acquisition. Elsevier; 2006, pp. 291-296.

13. Suchman RG. Visual impairment among deaf children. Arch Ophthalmol. 1967;77:18-21. https://doi.org/10.1001/archopht.1967.00980020020005

14. Chaurasia MK, Geddes NK. An analysis of the aetiology of early childhood deafness. Clin Otolaryngol. 1991;16:280-284. https://doi.org/10.1111/j.1365-2273.1991.tb00931.x

15. Bakhshaee M, Banaee T, Ghasemi MM, et al. Ophthalmic disturbances in children with sensorineural hearing loss. Eur Arch Oto-Rhino-Laryngol. 2009;266:823-825. https://doi.org/10.1007/s00405-008-0821-7
16. Mohindra I. Vision profile of deaf students. Am J Optom. 1976;53:412-419. https://doi.org/10.1097/00006324-197608000-00004

17. Woodruff E. Differential effects of various causes of deafness on the eye, refractive errors and vision of children. Am J Optom Physiol Optics. 1986;63:668-675. https://doi.org/10.1097/00006324-198608000-00011

18. Sharma A, Ruscetta MN, Chi DH. Ophthalmologic findings in children with sensorineural hearing loss. Arch Otolaryngol - Head Neck Surg. 2009;135(2):119123. https://doi.org/10.1001/archoto.2008.546 